\title{
Methodology for the design of industrial hydrogen networks and the optimal placement of purification units using multi-objective optimisation techniques
}

\author{
Luc Girardin $^{\mathrm{a}}$, François Marechal ${ }^{\mathrm{a}}$, Pascal Tromeur ${ }^{\mathrm{b}}$ \\ ${ }^{a}$ Laboratory for industrial energy system, Ecole polytechnique fédérale de Lausanne, \\ CH-1015 Lausanne, Switzerland. \\ ${ }^{b}$ Air Liquide, Centre de Recherche Claude-Delorme, Jouy-en-Josas, France.
}

\begin{abstract}
The optimal design of hydrogen networks aims at minimising the consumption of fresh hydrogen by improving recycling and reuse of process hydrogen. To solve this problem, a new graphical representation has been developed to characterize the minimum hydrogen requirement, and make a preliminary selection of the compatible purification units. From this preliminary analysis, a multi-objective optimisation method is applied in order to define the best hydrogen network and the proper integration of purification units. The proposed method decomposes the problem into two sub-problems : a mixed integer linear programming for network design at the lower level and an evolutionary algorithm strategy to solve the optimal design of the purification units at the upper level.
\end{abstract}

Keywords: Hydrogen network design, Hydrogen Pinch analysis, Multi-objective optimisation, Purification unit placement.

\section{Introduction}

\subsection{Problem statement}

In the refining industry, growing amount of hydrogen is needed for petroleum conversion and clean fuel production. The design of hydrogen networks in industrial production sites aims at minimizing the consumption of fresh hydrogen by optimizing the operating parameters, more and more by trying to recycle the degraded hydrogen produced in the process units, and by integrating hydrogen purification units. In this study, process units of the refinery are defined as hydrogen sources and sinks, each being defined by a hydrogen flow, purity, contaminant and pressure.

Considering the analogy heat load/flow rate (quantity) and temperature/purity (quality), the minimum hydrogen requirement may be defined by applying pinch based techniques A first representation has been proposed by [5], it was improved by [3] in the form of total flow rate - purity diagrams and surplus diagrams. The graphical methods suffer from the fact that these are not able to consider simultaneously purity and other contaminant constraints or the pressure constraints. Furthermore, these are not able to identify hydrogen consumption reduction obtained by reusing low grade hydrogen by mixing, although this operation is of common practice in the refining process. The use mathematical programming techniques appears to be more appropriate in order to consider simultaneously pressure constraints, contaminants restrictions and network topologies. A MINLP (Mixed Integer Non Linear Programming) hydrogen network model, which integrates compressor units, was proposed by [4] and solved after linearization as a MILP (Mixed Integer Linear Programming) problem. A method for integrating purification units in the hydrogen network was proposed by [1]. It uses 
relaxation techniques to allow algorithm convergence. This paper describes a multiobjective optimization methodology based on pinch concepts and mixed integer linear and non-linear programming to solve the minimum hydrogen requirement and the hydrogen network design problem. The major advantage of using the multi-objective optimization strategy is its ability to generate a list of Pareto optimal hydrogen system configurations that may be compared to synthesize the best solution.

\section{Hydrogen composite curves}

When using composite curves of suppliers and consumers using hydrogen flow rate $\left(\mathrm{h}_{\mathrm{i}}\right)$ - purity $\left(\mathrm{x}_{\mathrm{i}}\right)$ diagrams [3], it is easy to understand that the computed minimum hydrogen requirement will not be appropriately calculated by this method because this representation will not allow the identification of hydrogen reuse by mixing. Recycling by mixing is similar to a heat pump effect : a consumer takes low purity hydrogen below the pinch and upgrades its quality by mixing with high purity hydrogen to produce an hydrogen requirement of medium quality above the pinch. Therefore, in order to represent the mixing effect, we considered that a mixer is a device in which hydrogen sources decrease their hydrogen purity up to a depleted level $\left(\mathrm{x}_{0}=0\right)$ while hydrogen sinks increase their purity from the depleted level to the required purity. The analogy with the hot and cold composite is therefore trivial and allows computing the suppliers and consumers hydrogen composite curves and the corresponding minimum hydrogen requirement. Combining the two curves defines the hydrogen Grand composite curve, a limiting curve that is similar to the one of the water pinch representation [2] and against which the fresh hydrogen curve (the utility stream) can be plotted to define the minimum fresh hydrogen flow as a function of its purity (figure 1). In this representation, the total hydrogen flow is the slope of the utility curve whose fixed points are the fresh hydrogen purity and the depleted level that is common to all the hydrogen streams. According to the activation or not of the pinch points, the hydrogen flowrate may be higher then the minimum required and an excess of hydrogen will be read on the left of the $\mathrm{Y}$ axis. The use of purification units will allow to reduce the fresh hydrogen flow, by changing the pinch point location. Hydrogen of purity below the pinch point will feed a purification unit (figure 2) to produce high quality hydrogen above the pinch point and low purity hydrogen. The high quality hydrogen allows again an additional hydrogen reuse by mixing. This effect is illustrated on the integrated composite curves [7] of the purification unit given on figure 2. The modification of the hydrogen pinch point resulting from the integration of a purification unit allows the reduction of the fresh hydrogen flowrate.

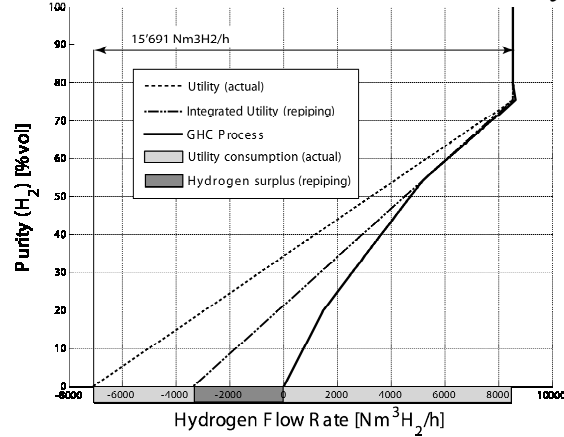

Figure 1 : integrated composite curve of the fresh hydrogen integration

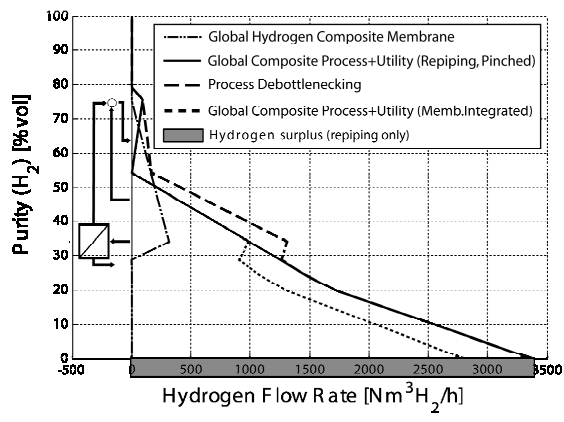

Figure 2 : integrated composite curve of the purification unit integration 


\section{Multi-objective optimization strategy}

Although the graphical representation allows understanding the hydrogen network integration, to compute the hydrogen requirement and to identify the possible integration of purification unit, it does not allow to consider all the important constraints of the hydrogen network design like contaminant and/or pressure and compression constraints, piping and repiping, as well as depleted hydrogen valorization. For solving such problem, mathematical programming formulations have to be used. The optimal hydrogen network design problem is stated as :

- Minimize: $\quad \mathrm{C}_{\text {year }}(\underline{\mathrm{x}})=\mathrm{C}_{\mathrm{H} 2}+\mathrm{IC}_{\text {pipe }}+\mathrm{IC}_{\text {comp }}+\mathrm{IC}_{\text {pur }}+\mathrm{OC}_{\text {comp }}+\mathrm{OC}_{\text {pur }}-\mathrm{S}_{\mathrm{H} 2}$ - Under constraints : $\mathrm{g}(\underline{\mathrm{x}}, \underline{\mathrm{y}})=0$,

where $\mathrm{C}_{\mathrm{year}}(\underline{\mathrm{x}})$ is the sum of annual operating and investment costs, $\mathrm{C}_{\mathrm{H} 2}$ fresh hydrogen cost, it accounts for the investment and the production costs of the hydrogen sources. $\mathrm{IC}_{\text {pipe, }} \mathrm{IC}_{\text {comp }}, \mathrm{IC}_{\text {pur }}$ respectively annualised investment cost of piping, compressors and purification units, $\mathrm{OC}_{\text {comp }}, \mathrm{OC}_{\mathrm{pur}}$ respectively operating cost of compression and purification untis, $\mathrm{S}_{\mathrm{H} 2}$ selling of the depleted hydrogen. It is interesting to note that as the major contaminant is methane, the lower heating value and therefore the selling price of depleted hydrogen is increasing when the purity is decreasing. Recycling of hydrogen with the highest possible purity is then favored by this formulation.

$\underline{\mathrm{X}}$ are the decision variables: i.e. the existence and the flowrates in the pipes of the network, the selection and the flowrate of the fresh hydrogen sources as well as the existence, the operating conditions and the sizes of the purification units. $\mathrm{g}(\underline{\mathrm{x}}, \underline{\mathrm{y}})$ are the linear and non linear constraints equations.

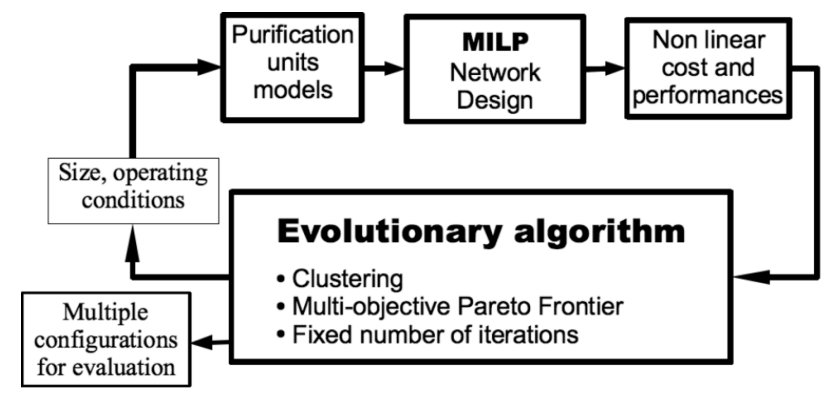

Figure 3 : the solving procedure algorithm.

As described on figure 3, this MINLP problem is solved by decomposing it (variables and constraints) into two sub-problems. The upper level uses an evolutionary algorithm to compute the characteristics and optimal operating conditions of the purification units while the network is designed by solving a Mixed Integer Linear Programming problem at the lower level.

\subsection{The hydrogen network superstructure.}

The hydrogen network is modeled as a superstructure that contains all the feasible connections between hydrogen sources and sinks of the process. The decision variables for the MILP problem are : the hydrogen flow rate between sink and sources $\left(\dot{h}_{p, c}\right.$ $\left.\left[\mathrm{Nm}^{3} \mathrm{H}_{2} / \mathrm{h}\right]\right)$, the connection existence $\left(y_{p, c}\{0,1\}\right)$, the units utilisation level ( $\left.q_{u}[-]\right)$. In this model, the purity, contaminants, pressures and hydrogen flowrate are assumed to be constant and it is assumed that the operating conditions of the process units will not 
change if the hydrogen purity is higher than the present consumption. When defining the requirement, we consider the hydrogen quality that is really required at the inlet of the process units. When a recycling system is already in use, it only defines an existing connection that will be favored but it is not imposed a priori in order to allow new connections by repiping. A utilization level $\left(\mathrm{q}_{\mathrm{u}}\right)$ is associated with each process units and will multiply all the flowrates (sources and sinks) associated with the unit. A purification unit is defined in the same way, introducing one hydrogen sink (medium purity) and two hydrogen sources (one of high purity and one of low purity (lean stream). For these units, the purity and the nominal flows are considered as constant and will define the unit size and the corresponding investment. For such units, the level of utilization will only affect the operating cost. Each unit is geo-referenced and a piping path is estimated in order to account for pressure drops, existing pipes and new piping costs. The linear programming model is stated as follows. The investment costs are linearised functions.

$$
\text { Minimize } \mathrm{C}_{\text {year }}(\underline{\mathrm{x}})=\mathrm{C}_{\mathrm{H} 2}+\mathrm{IC}_{\text {pipe }}+\mathrm{IC}_{\text {comp }}+\mathrm{IC}_{\text {pur }}+\mathrm{OC}_{\text {comp }}+\mathrm{OC}_{\text {pur }}-\mathrm{S}_{\mathrm{H} 2}
$$

$$
\dot{m}_{p} q_{u}(p)-\sum_{c=1}^{n_{c}(p)} \dot{h}_{p, c}=\dot{m}_{\text {out }}, \forall p=1, \ldots, n_{p} \quad \begin{aligned}
& \text { Hydrogen } \\
& \text { production } \\
& \text { constraint }
\end{aligned}
$$

$\sum_{p=1}^{n_{p, c}} \dot{h}_{p, c}=\dot{m}_{c} q_{u}(c), \forall c=1, \ldots, n_{c}$

Hydrogen demand

requirement

$\sum_{p=1}^{n_{p}} \frac{\dot{h}_{p, c}}{X_{p}} \cdot\left(1-X_{p}\right) \leq \frac{\dot{m}_{c} q_{u}(c)}{X_{u}} \cdot\left(1-X_{c}\right), \forall c=1, \ldots, n_{p}$

Impurity demand

restrictions

$\sum_{p=1}^{n_{p}} \frac{\dot{h}_{p, c}}{X_{p}} \cdot x_{p,[s p e c]} \leq \frac{\dot{m}_{c} q_{u}(c)}{X_{u}} \cdot x_{c,[s p e c]}^{\max }, \forall c=1, \ldots, n_{p}$

Specific impurity

demand restrictions

$y_{p, c} \cdot \dot{h}_{\min } \leq \dot{h}_{p, c} \leq y_{p, c} \cdot 1.1 \cdot \min \left(\dot{m}_{p}^{\max }, \dot{m}_{c}^{\max }\right)$

Flow rate constraint

$w_{p, c}=\left\{\begin{array}{l}y_{p, c} \cdot \frac{1}{X_{p}} \cdot \frac{1}{\eta_{c}} \cdot \frac{\gamma}{\gamma-1} \cdot k \cdot R \cdot T_{p} \cdot\left(\left\{P_{c} /\left(P_{p}-\Delta p_{p, c}\right)\right\}^{\frac{\gamma-1}{\gamma}}-1\right) \text { if } P_{p} \leq P_{c} \\ 0 \text { if } P_{p}>P_{c}\end{array}\right.$

Compression power

$y_{p, c}=0, p \in\left\{1, \ldots, n_{p}\right\}, c \in\left\{1, \ldots, n_{p}\right\}$

Unfeasible

connections

A parametrized heuristic rule is added to limit the number of feasible connections by considering a maximum expected pay back time of each pipe. The limiting pay back time is considered as a decision variable of the upper level.

\subsection{The upper level model}

The definition of the hydrogen sources and sinks of the purification units are defined in the upper level using an evolutionary algorithm. In the non linear problem, the decision variables for each of the proposed purification units are the hydrogen nominal flowrate in the purification units $\left(\dot{h}_{f}\left[\mathrm{Nm}^{3} \mathrm{H}_{2} / \mathrm{h}\right]\right)$, the feed purity $\left(x_{f}\left[\mathrm{kmolH}_{2} / \mathrm{kmol}\right]\right)$, the feed total pressure $\left(P_{f}[\mathrm{bar}]\right)$, the product total pressure $\left(P_{p}[\mathrm{bar}]\right)$, the product hydrogen purity $\left(x_{p}\left[\mathrm{kmolH}_{2} / \mathrm{kmol}\right]\right)$ and the geo-referenced unit position $(p x, p y[\mathrm{~m}])$. Using thermo-economic data from [8] for purification units, the performances of the units are 
modeled and define the data for the network design model. Cost are estimated considering the nominal size defined in the upper level.

\subsection{Solving the multi-objective optimization problem}

The use of an evolutionary algorithm to solve the upper level problem allows to use a multi-objective optimization strategy. The evolutionary algorithm [6] generates Pareto optimum frontier. It does not require the coding of continuous variables and works with clustering techniques that allow isolating different systems configurations. The objective functions are the operating cost (that relates to the hydrogen recovery) and the investment cost. From the results of the lower level problem, non linear costing of the piping and the unit investment are performed. The evolutive solver tries to improve solutions by proposing new admissible operating points. The algorithm proceeds like this until it reaches a fixed number of iterations. This resolution scheme has several advantages over schemes that solve simultaneously a set of MINLP equations:

- its modularly aspect is suitable for adding new models equations.

- it can track several design objective simultaneously,

- it generate multiple clusters of solutions.

- It allows to handle problem discontinuities (e.g. unit design conditions and purity optimisation)

\section{Case study}

The problem to be solved is the retrofit of a hydrogen recovery network. The process sources and sinks are given in table 1. The fresh hydrogen actual consumption is of $15691 \mathrm{Nm}^{3} \mathrm{H}_{2} / \mathrm{h}$ (figure 1). The results are presented in the form of the Pareto curve of figure 4 . The different tics shapes are used to identify the different solution clusters found by the algorithm. Each point corresponds to a different hydrogen recovery configuration. For the analysis, each configuration is represented automatically. Figure 5 gives an example of a network configuration, the dashed lines represent new connections, the size of connections are proportional to the hydrogen flow. The results show a hydrogen saving ranging from $24 \%$ to $29 \%$ with pay back time from 1 to 5 years.

Table 1 : producers and consumers for the problem

\begin{tabular}{ccrrcrrrr}
\hline & $\begin{array}{c}\text { Flow rate } \\
\text { Producers }\end{array}$ & $\begin{array}{l}\text { Purity } \\
{\left[\mathrm{Nm}^{3} / \mathrm{h}\right]}\end{array}$ & $\begin{array}{l}\text { Pressure } \\
{[\% \text { vol] }}\end{array}\left[\begin{array}{l}\text { bar }] \\
\text { Consumers }\end{array}\right.$ & $\begin{array}{l}\text { Flow rate } \\
{\left[\mathrm{Nm}^{3} / \mathrm{h}\right]}\end{array}$ & $\begin{array}{l}\text { Purity } \\
{[\% \text { vol }]}\end{array}$ & $\begin{array}{l}\text { Pressure } \\
{[\mathrm{bar}]}\end{array}$ \\
\hline FRESH & 18246 & 75.6 & 23.6 & G_IN & 35.4 & 75.6 & 29.6 \\
A_BP & 558.6 & 20 & 17 & A_IN & 11517 & 75.6 & 29.6 \\
A_HP & 10323 & 79.3 & 17 & B_IN & 5170.8 & 79.1 & 31 \\
B_BP & 160.2 & 25 & 26 & C_IN & 7232.4 & 79.2 & 46.4 \\
B_HP & 852.6 & 78.6 & 26 & E_IN & 35.4 & 75.6 & 29.6 \\
C_BP & 2899.8 & 54.2 & 33.9 & F_IN & 2494.8 & 75.6 & 32.6 \\
C_HP & 2611.8 & 79.1 & 33.9 & D_IN & 8406.6 & 79.3 & 17 \\
D_OUT & 8938.8 & 79.3 & 17 & & & & \\
\hline
\end{tabular}




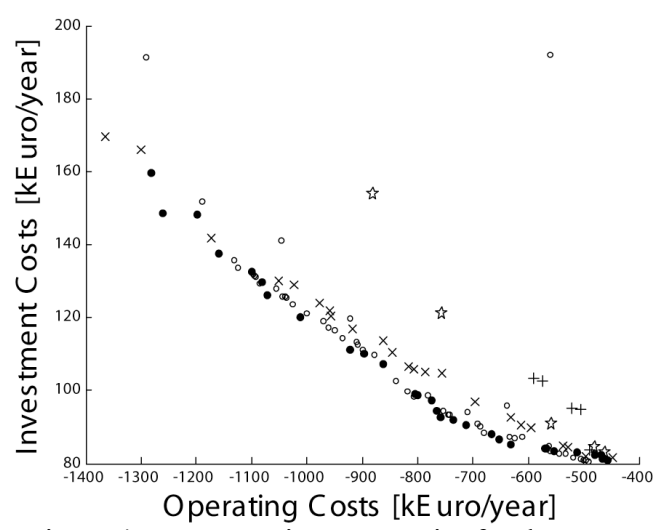

Figure 4 : Pareto optimum Frontier for the problem

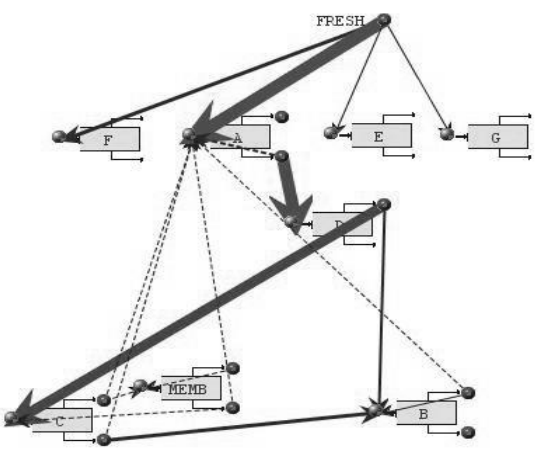

Figure 5 : example of network representation

\section{Conclusion}

Combining evolutionary algorithm and MILP network design models, a multi-objective optimization methodology has been developed to solve the hydrogen recovery network design problem considering the integration of purification units. The major advantage of using the multi-objective optimisation strategy is the generation of a list of Pareto optimal process configurations. Each of the configurations can then be analysed from practical point of view in order to define the best configuration. The developed methodology has been applied to solve real scale problems. The best configurations show hydrogen savings as high as $29 \%$ with reasonable pay back.

\section{References}

[1] Liu, F. and Zhang, N., Strategy of purifier selection amd integration in hydrogen networks, Chemical. Engineering Research and Design, Vol 82, pp. 1315-1330, (2004)

[2] Y. Wang and R. Smith. Wastewater minimisation. Chemical Engineering Science, 49(7):1981-1006, (1994).

[3] Alves, J. and Towler, P., 2001. Analysis of Refinery Hydrogen Distribution Systems Ind. Eng. Chem. Res., Vol 41, pp. 5759-5769, (2002).

[4] Hallale,N. and Liu, F., Refinery hydrogen management for clean fuels production, Advances in Environmental Research, Vol 6, pp. 81-98, (2001)

[5] Towler, G.P., Mann, R., Serrierre, A. J-L. and Gabaude, C., Refinery Hydrogen Managment: Cost Analysis of Chemically-Integrated Facilities, Ind. Eng. Chem. Res. , Vol 35, pp. 23782388, (1996).

[6] Molyneaux, A., Favrat, D., and Leyland, G.. A New Clustering Evolutionary Multi-Objective Optimisation Technique. In Third International Symposium on Adaptative Systems, Institute of Cybernetics, Mathematics and Physics, pages 41-47, 2001.

[7] Marechal, F. and Kalitventzeff, B. Targeting the minimum cost of energy requirements : a new graphical technique for evaluating the integration of utility systems. Computers chem. Engng, 20(Suppl.):S225-S230, 1996.

[8] Bhide, B.D, Stern, S.A, Membrane processes for the removal of acid gases from natural gas, Journal of Membrane Science, Vol 81, pp. 209-237, (1993). 